\title{
Targeting the differentiation of gastric cancer cells (KATO-III) downregulates epithelial-mesenchymal and cancer stem cell markers
}

\author{
SHAHID SHAH ${ }^{1,2}$, MARC POCARD ${ }^{1}$ and MASSOUD MIRSHAHI ${ }^{1}$ \\ ${ }^{1}$ University of Sorbonne Paris Cité-Paris 7, Lariboisière Hospital, INSERM U965, 75010 Paris, France; \\ ${ }^{2}$ Department of Pharmacy Practice, Faculty of Pharmaceutical Sciences, \\ Government College University, 38000 Faisalabad, Pakistan
}

Received September 11, 2018; Accepted May 17, 2019

DOI: 10.3892/or.2019.7198

\begin{abstract}
The aim of the present study was to analyze the acquisition of the differentiated phenotype in the human gastric signet ring cell adenoma cancer KATO-III cell line in vitro. The morphology of KATO-III cells was explored by microcinematography. Different cytokines secreted by both adherent and non-adherent KATO-III cells into medium were observed. The cancer stem cell phenotypes were identified by reverse transcription-quantitative polymerase chain reaction using primers (E-Cad, Slug, Snail, vimentin, NANOG, NESTIN, OCT3/4 and C-X-C motif chemokine receptor 4) or antibodies [cluster of differentiation (CD)90 and CD117] by flow cytometry (FACS). The influence of the induction media for the differentiation of mesenchymal cells was studied through viability and proliferation assays, by evaluating gene expression and the expression of markers via FACS. Cell viability and cell cycle distribution were evaluated following the treatment of KATO-III with acetyl salicylic acid and using the induction media as an inhibitor of epithelial-mesenchymal transition (EMT) and heparanase. A total of 3 phenotypes of KATO-III were observed (adherent, non-adherent and cell cluster), which have internal potential for cell transition into one of the other phenotypes. KATO-III was differentiated into adipocyte-, chondrocyte-, osteocyte- and neurocyte-like cells by the induction media. Identification of the induced cells was conducted using cell dyes. Reduced mRNA expression of EMT-associated molecules, stem cell markers and heparanase was observed with acetyl salicylic acid and induction media. An inhibitory effect of acetyl salicylic acid and the induction
\end{abstract}

Correspondence to: Dr Massoud Mirshahi, University of Sorbonne Paris Cité-Paris 7, Lariboisière Hospital, INSERM U965, 41 Bd de la Chapelle, 75010 Paris, France

E-mail: massoud.mirshahi@inserm.fr

Key words: acetyl salicylic acid, differentiation, epithelialmesenchymal transition, heparanase, KATO-III cell line, Signet ring cell adenocarcinoma media was also noted in regard to cell proliferation. In addition, acetyl salicylic acid induced G0/G1 phase cell cycle arrest in KATO-III cells. In conclusion, the induction of the differentiation of cancer stem cells into non-proliferating cells offers the possibility for novel drug design to overcome the issues associated with metastasis, drug resistance and systemic toxicity with improved therapeutic efficacy.

\section{Introduction}

Gastric signet ring cell adenocarcinoma (SRCA) is characterized by the presence of isolated or small groups of malignant non-cohesive cells (1). The characteristics of SRCA are its resistance to chemotherapy (2), tissues fibrosis and peritoneal invasion (3). Recently we reported the upregulated expression of heparanase in SRCA, which is involved in the acquisition of the mesenchymal phenotype and tumor cell malignancy (4). In the present study, it was also revealed that the epithelial-mesenchymal transition (EMT) process could be inhibited by suramin, an heparanase inhibitor. A recent study revealed that non-steroid anti-inflammatory drugs such as acetyl salicylic acid inhibit proliferation and induce cell cycle arrest as well as apoptosis in different cancer cells (5). Previously, we reported that an ovarian cancer cell line, OVCAR-3 NIH, expressed both cluster of differentiation (CD)-133 and CD-117 stem cell markers and secreted cytokines implicated in tumor growth and cell differentiation (6). In another previous study, it was indicated that poorly differentiated ovarian cancer cells with a high proliferative index could be transported to other tissues with no proliferation potential (7).

The differentiation of cancer cells to non-proliferated cells is well known. Previously, 35 years ago, Flynn et al (8) described the use of 13-cis-retinoic acid for the treatment of acute promyelocytic leukemia (APL).Today, recent clinical trials have demonstrated that the majority of patients with APL could be definitively cured by the combination of 2 targeted therapies: Retinoic acid and arsenic (9). APL cells have immature characteristics and can be differentiated to other non-proliferative myelocyte cell lines (10). This example justifies the investigation of differentiation-inducing factors in solid tumor therapy. In a variety of solid tumors, a subpopulation of tumorigenic 
cells was identified as cancer stem cells (CSCs) (11). These CSCs have the ability to initiate tumor growth in immunocompromised mice (12). CSCs, by giving rise to a large population of differentiated progeny, make up the bulk of the tumor but they lack tumorigenic potential (13). An association between CSC and epithelial-mesenchymal transition (EMT) has been attributed (14) and these CSCs could acquire the differentiated phenotype following cytotoxic chemotherapy (15).

On the basis of the pluripotency of CSC, the aim of the present study was to demonstrate that the gastric cancer cell line, KATO-III, with a high proliferative tendency could be inhibited and differentiated into other cells in vitro using cell-differentiating inductors.

\section{Materials and methods}

Cell lines and reagents. The human SRCA cell line used KATO-III was obtained from the American Type Culture Collection (ATCC). The primary drug used, acetyl salicylic acid (Aspegic), was purchased from Sanofi-Aventis.

Cell culture. Cells were cultured in Iscove's modified Dulbecco's medium (IMDM) containing 10\% heat-inactivated fetal bovine serum (FBS), $50 \mu \mathrm{g} / \mathrm{ml}$ of streptomycin, $50 \mathrm{IU} / \mathrm{ml}$ of penicillin and $2 \mathrm{nM}$ of L-glutamine (Gibco; Thermo Fisher Scientific, Inc.). Cells were incubated at $37^{\circ} \mathrm{C}$ in a humidified atmosphere containing $5 \% \mathrm{CO}_{2}$

Cytokine array. The present study examined the supernatant of KATO-III cells grown in serum-free IMDM using a protein cytokine array (RayBio ${ }^{\circledR}$ Human Cytokine Antibody; RayBiotech Life); this technique is based on the principle of the sandwich immunoassay (16). It consists of screening, in duplicate, 174 different membrane-coupled anti-cytokines along with the appropriate controls (experiments were repeated 3 times).

KATO-III cells were incubated in IMDM at $37^{\circ} \mathrm{C}$ in a humidified atmosphere of $5 \% \mathrm{CO}_{2}$ for $24 \mathrm{~h}$. Non-adherent cells $\left(10^{6}\right.$ cells $\left./ \mathrm{ml}\right)$ from the culture flask were recovered by centrifugation $(130 \mathrm{x} \mathrm{g})$, washed with PBS (1X) and then re-suspended in serum-free IMDM. Concurrently, adherent cells from the same flask were washed with PBS (1X) and then incubated in the same conditions as those applied for non-adherent cells.

Following $24 \mathrm{~h}$, the supernatants containing cytokines from adherent and non-adherent cells were retrieved and cytokines were allowed to couple with their specific antibodies previously immobilized on the nitrocellulose membranes. The membranes were saturated for $2 \mathrm{~h}$ at room temperature with bovine serum albumin (BSA). Incubation of the array membranes with supernatants was conducted overnight at $4^{\circ} \mathrm{C}$ using the corresponding antibodies. Following several successive washes, the membranes were incubated in the presence of a mixture of antibodies and anti-cytokines biotinylated antibodies at $4^{\circ} \mathrm{C}$ overnight. Streptavidin, coupled with horseradish peroxidase (HRP), was added to the membranes for $2 \mathrm{~h}$ at room temperature. The presence of the antibody-coupled proteins was evaluated by applying enhanced chemiluminescence $\left(\right.$ RayBio $^{\circledR}$ ) to the membranes, according to the recommendations of the manufacturer. Membranes were then exposed to photosensitive film (Kodak X-OMAT; Kodak).
The intensity of chemiluminescence captured on the photosensitive film was measured and recorded. Once the background noise was removed, the results were expressed as a ratio of chemiluminescence intensity of the experimental vs. control spots. The positive control was considered to be 1 ; a ratio value $<-5$ indicated a reduction of the cytokine and a value $>+5$ indicated an increase in cytokine expression.

RNA isolation, reverse transcription $(R T)$ and quantitative polymerase chain reaction ( $q P C R$ ). RNA isolation, RT and qPCR. Total RNA from the cells was extracted using a Qiagen RNeasy Mini kit (Qiagen $\mathrm{GmbH}$ ) according to the manufacturer's instructions. RNA samples $(70 \mathrm{ng} / \mu \mathrm{l})$ were transcribed to cDNA in a $20-\mu 1$ volume, using the QuantiTect Reverse Transcription kit (Qiagen $\mathrm{GmbH}$ ). The mRNA expression levels of the different markers were detected by qPCR with $\beta$-actin as the internal reference, using Mesa Blue qPCR Master Mix Plus for SYBR ${ }^{\circledR}$ assay (Eurogentec Ltd.) on the Mastercycler ${ }^{\circledR}$ Realplex2 (Eppendorf).The thermocycling conditions for RT-qPCR were as follows: $95^{\circ} \mathrm{C}$ for $5 \mathrm{~min}$, followed by 40 cycles of denaturation for $15 \mathrm{sec}$ at $95^{\circ} \mathrm{C}$, annealing for $20 \mathrm{sec}$ at $60^{\circ} \mathrm{C}$ and extension for $20 \mathrm{sec}$ at $72^{\circ} \mathrm{C}$. The primer sequences and PCR product size for the target and reference genes are listed in Table SI.

Relative quantification was performed using the comparative quantitative cycle $(\mathrm{Cq})$ method with Realplex software. The mean $\mathrm{Cq}$ of triplicate measurements was used to calculate $\Delta \mathrm{Cq}$ as the difference in $\mathrm{Cq}$ for the target and internal reference ( $\beta$-actin) genes. The difference between the $\Delta \mathrm{Cq}$ of the control experiment (KATO-III) and the $\Delta \mathrm{Cq}$ of each sample were calculated to produce $\Delta \Delta \mathrm{Cq}$. The fold increase in mRNA was calculated using the $2^{-\Delta \Delta \mathrm{Cq}}$ method (17). The PCR products of the cell lines following RT-qPCR were electrophoresed by E-Gel Precast Agarose Electrophoresis System (Invitrogen).

Fluorescence-activated cell sorting (FACS) analysis. Confluent KATO-III cells $\left(0.1 \times 10^{6}\right)$ were seeded in a $25-\mathrm{cm}^{2}$ culture flask, followed by $24 \mathrm{~h}$ in either control or inductor media (StemPro ${ }^{\circledR}$ Adipogenesis, Chondrogenesis, Osteogenesis Differentiation kit and Neurobasal ${ }^{\circledR}$ medium) for 14 days or with $4.5 \mathrm{mM}$ acetyl salicylic acid for 6 days.

The cells and tumor spheres were dissociated as a single cell suspension, washed with PBS and then labeled with antibodies (10 $\mu \mathrm{l} / 1 \times 10^{6}$ cells), including mouse anti-human CD90 (2:100 dilution; cat. no. 559869; BD Biosciences) and CD117 (7:100 dilution; cat. no. 550412; BD Biosciences) at $4^{\circ} \mathrm{C}$ in the dark for $30 \mathrm{~min}$. The samples (minimum 10,000 cells) were analyzed by flow cytometry (FACSAria II; BD Biosciences).

Cell cycle distribution analysis. Cell cycle distribution was analyzed using the Click-iT ${ }^{\mathrm{TM}}$ Plus EdUAlexa Fluor $647^{\mathrm{TM}}$ Flow Cytometry Assay Kit (Thermo Fisher Scientific, Inc.), according to the manufacturer's protocol. The KATO-III cell line was incubated with IMDM and 5\% FBS for $24 \mathrm{~h}$. The following day, the cells were treated with or without $4.5 \mathrm{mM}$ acetyl salicylic acid. Following 4 days of treatment, the cells were trypsinized, harvested and incubated in culture medium with $15 \mu \mathrm{MEdU}$ for $2 \mathrm{~h}$. After incubation, the cells were washed with $1 \%$ BSA in PBS and $100 \mu \mathrm{l}$ of Click-iT fixative was added for $15 \mathrm{~min}$ at room temperature. Following washing, 
A
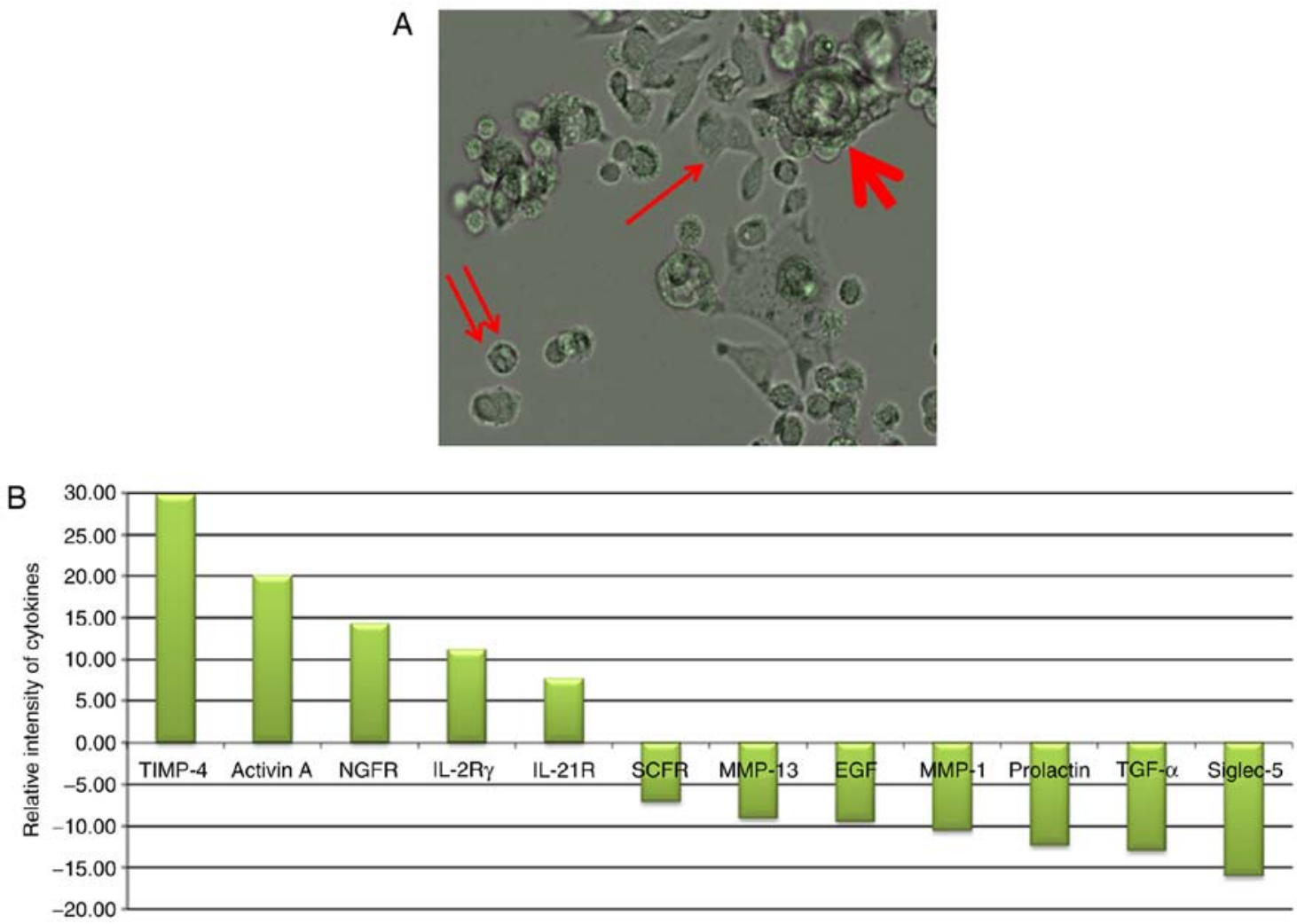

Figure 1. Spheroid cluster formation and significantly different expression ratio of cytokines (adherent/non-adherent) in the KATO-III cell line (fold-change $>5$; $\mathrm{P}<0.05$ ). (A) KATO-III cells form adherent (arrow), non-adherent (double arrow) and cell clusters (bold arrow; some were also non-adherent. (B) Of the 174 proteins proposed in this test only 12 cytokines were reported to be significant in the ratio of cytokine expression in adherent/non-adherent KATO-III cell line. $\mathrm{P}<0.05$.

the cells were incubated with the Click-iT Plus reaction cocktail including fluorescent dye (Alexa Fluor 647 picolylazide) for $30 \mathrm{~min}$. The flow cytometric analysis was performed using a BD LSR II analytical flow cytometer (BD Biosciences). MultiCycle AV (Phoenix Flow Systems) DNA analysis software enabled the determination of the phase of cell cycle arrest by comparing the percentages of each cell stage (G1, S and $\mathrm{G} 2 / \mathrm{M}$ ) between the control and treatment groups.

Cell viability assay. Cell viability was assayed by a RealTimeGlo $^{\mathrm{TM}}$ kit containing the MT Cell Viability Substrate and the NanoLuc ${ }^{\circledR}$ Enzyme from Promega Corp. Briefly, confluent KATO-III cells $\left(3 \times 10^{3} /\right.$ well) were seeded on 96-well plates, and then $24 \mathrm{~h}$ later in either control or conditional medium with acetyl salicylic acid or inductor media (StemPro ${ }^{\circledR}$ Adipogenesis, Chondrogenesis, Osteogenesis Differentiation Kit and Neurobasal ${ }^{\circledR}$ medium).

Reagents were added directly to the cell culture and the bioluminescence was measured at different time intervals $(0,12,24,48,72$ and $96 \mathrm{~h})$ with a Xenius XC spectrofluorometer (SAFAS, Monaco). Cell viability was expressed as the percentage of the absorbance of the drug-treated cells relative to that of the vehicle-treated cells. Each condition was tested in triplicate. The results are representative of 3 independent experiments.

Differentiation of the KATO-III cell line. To induce adipogenic, chondrogenic, osteogenic and neurogenic differentiation, confluent KATO-III cells were incubated for 14 days with the StemPro ${ }^{\circledR}$ Adipogenesis, Chondrogenesis, Osteogenesis Differentiation kit (Gibco; Thermo Fisher Scientific, Inc.) and Neurobasal ${ }^{\circledR}$ medium (Thermo Fisher Scientific, Inc.). All induced cells were fixed for $30 \mathrm{~min}$ in $4 \%$ paraformaldehyde at room temperature and washed with PBS. For the assessment of calcium deposition in induced osteocytes, cells were treated with $2 \%$ Alizarin Red S solution ( $\mathrm{pH} 4.2$ ) for 2-3 min. The induced chondrocyte aggregates were stained with $1 \%$ Alcian Blue solution prepared in $0.1 \mathrm{~N} \mathrm{HCl}$ for $30 \mathrm{~min}$ and rinsed with distilled water to neutralize the acidity. The induced adipocytes were incubated with $60 \%$ isopropanol for $5 \mathrm{~min}$ and then stained with $60 \%$ Oil Red O $(0.3 \mathrm{~g} / \mathrm{ml}$ isopropanol $)$ in distilled water for $5 \mathrm{~min}$. The induced neurocytes were stained with cresyl violet solution $(0.5 \mathrm{~g}$ cresyl violet in $100 \mathrm{ml}$ of $0.6 \%$ glacial acetic acid) for $30 \mathrm{~min}$. An inverted microscope was used to image of all stained cells.

Statistical analysis. Data were analyzed using Student's t test and one- or two-way analysis of variance (ANOVA), followed by post-hoc Bonferroni's multiple comparison test when appropriated. Calculations were performed using commercial software (GraphPad Prism version 7.01 for Windows; GraphPad Software, www.graphpad.com). A two-sided $\mathrm{P}<0.05$ was retained for statistical significance.

\section{Results}

KATO-III cell line in vitro. As presented in Fig. 1A, the gastric cancer cell line KATO-III was observed in 3 forms in 

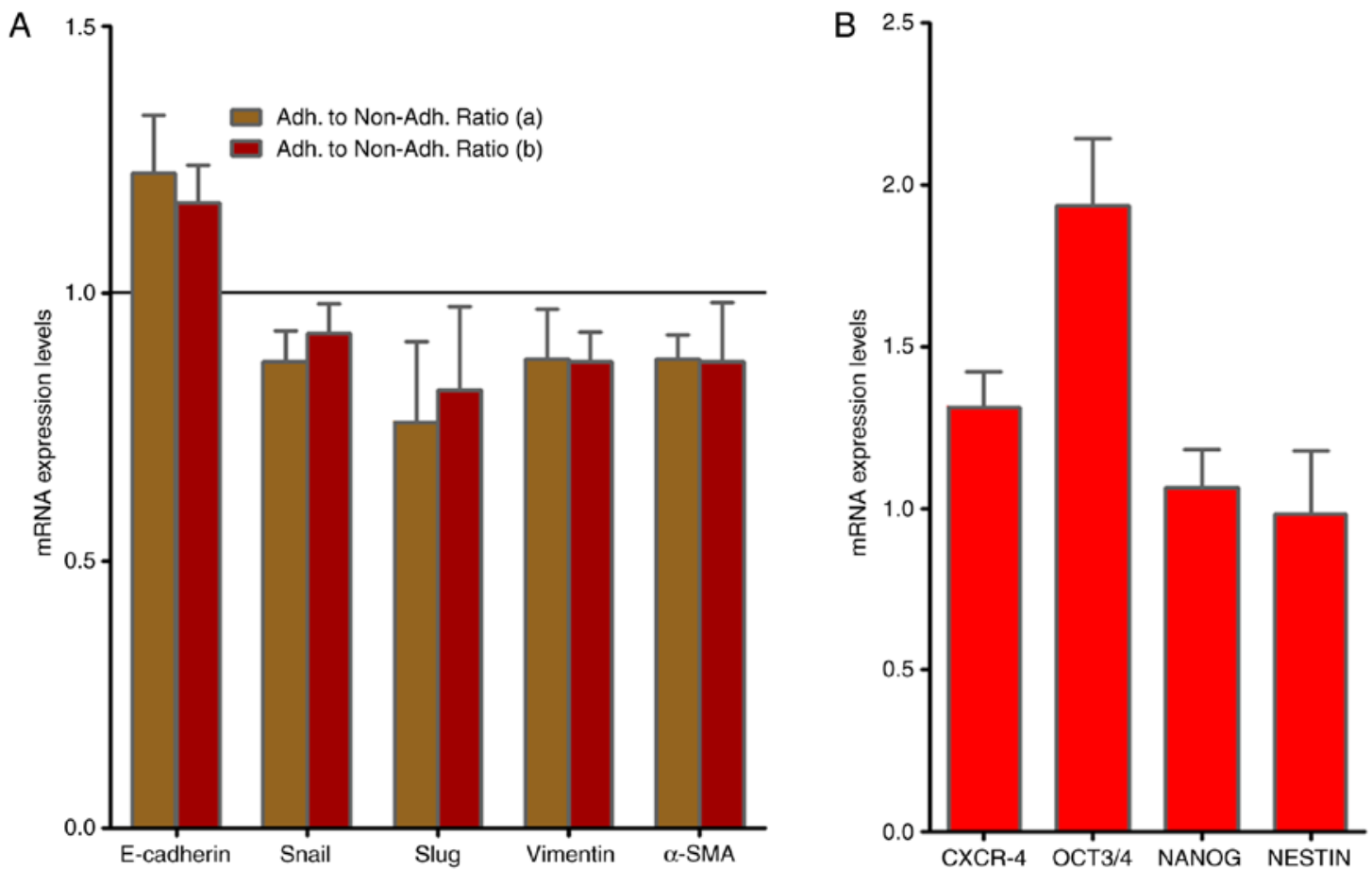

Figure 2. mRNA gene expression of EMT-associated genes and stem cell markers in the KATO-III cell line. (A) RT-qPCR analysis revealed no alterations in the gene expression of EMT-associated molecules when adherent and non-adherent KATO-III cells were grown separately (a) prior to and (b) following 1 week ( $\mathrm{P}<0.05)$. (B) mRNA gene expression of stem cell markers (CXCR-4, NANOG, OCT3/4 and NESTIN) in the KATO-III cell line via RT-qPCR. EMT, epithelial-mesenchymal transition; RT-qPCR, reverse transcription-quantitative polymerase chain reaction; CXCR-4, C-X-C chemokine receptor type 4; OCT3/4, octamer-binding transcription factor $3 / 4$.

the culture medium. Adherent cells (indicated by an arrow), non-adherent cells (indicated by a double arrow) and cell clusters (indicated by a bold arrow; some were also non-adherent) were observed. When these cells (adherent, and combined isolated and cluster forms of non-adherent single) were grown separately in culture medium, they subsequently generated other forms. These results are indicative of the internal potential of cell transition in conditional medium. The profile of cytokines secreted under each condition is presented in Fig. 1B. The results revealed the high secretion of tissue inhibitor of metalloproteinase-4 (TIMP-4), Activin A, nerve growth factor receptor (NGFR), interleukin (IL)-2R $\gamma$ and IL-21R in adherent cells and stem cell factor receptor (SCFR), matrix metalloproteinase (MMP)-13, epidermal growth factor (EGF), MMP-1, Prolactin, transforming growth factor (TGF)- $\alpha$, and sialic acid binding immunoglobulin-like lectin-5 (Siglec-5) in non-adherent conditions.

KATO-III cells present CSC as well as EMT markers. As presented in Fig. 2A, RT-qPCR analysis demonstrated no alterations in the gene expression of the EMT-associated molecules, Slug, vimentin and $\alpha$-smooth muscle actin (SMA) mRNAs when adherent and non-adherent KATO-III cells were grown separately for 1 week. By contrast, the presence of the CSC markers C-X-C chemokine receptor type 4 (CXCR-4), octamer-binding transcription factor (OCT)-3/4 as well as NANOG and NESTIN were confirmed in KATO-III cells as revealed in Fig. 2B.

Acetyl salicylic acid modifies heparanase, EMT and CSC marker expression in KATO-III cells in vitro. When KATO-III cells were incubated (2, 4 and 6 days) with acetyl salicylic acid (4.5 mM), their morphology gradually changed (Fig. S1). Inhibition of cell proliferation $(\mathrm{P}=0.002$; Fig. 3A) and significant downregulation of heparinase $(\mathrm{P}=0.0289)$ expression in the SRCA cell line was observed in a time-dependent manner(Fig. 3B). Mesenchymal markers such as Slug, vimentin and $\alpha$-SMA $(\mathrm{P}=0.004)$ were downregulated while E-cadherin was upregulated ( $\mathrm{P}=0.004$; Fig. $3 \mathrm{C})$. Acetyl salicylic acid also decreased the expression of the stem cell markers, CXCR4, OCT3/4, NANOG and NESTIN (P=0.004; Fig. 3D), and CD90 and CD117 (Fig. 3E). This phenomenon was associated with the inhibition of cell proliferation as well as EMT inhibition via the downregulation of heparanase and CSC markers.

Acetyl salicylic acid modifies the cell cycle in KATO-III cells. Flow cytometry was used for cell cycle analysis as revealed in Fig. 4A. The majority of the cells presented an increase in the number of cells in the G0-G1 phase (20\%). By contrast, this phenomenon was associated with a reduced number of cells in the $\mathrm{S}$ phase (reduction of $38 \%$ when compared with the control; Fig. 4B). These results indicated that acetyl salicylic acid via the G0-G1 phase pathway inhibits cancer cell proliferation.

Cell inducer differentiation media downregulates heparanase and stem cell marker expression as well as the inhibition of cell proliferation. When the SRCA cell line was incubated with different culture media targeting stem cell differentiation in adipocytes, chondrocytes, osteocytes and neuronal cells, the expression of heparanase significantly decreased as observed in adipocytes $(\mathrm{P}=0.005)$, chondrocytes $(\mathrm{P}=0.004)$ 

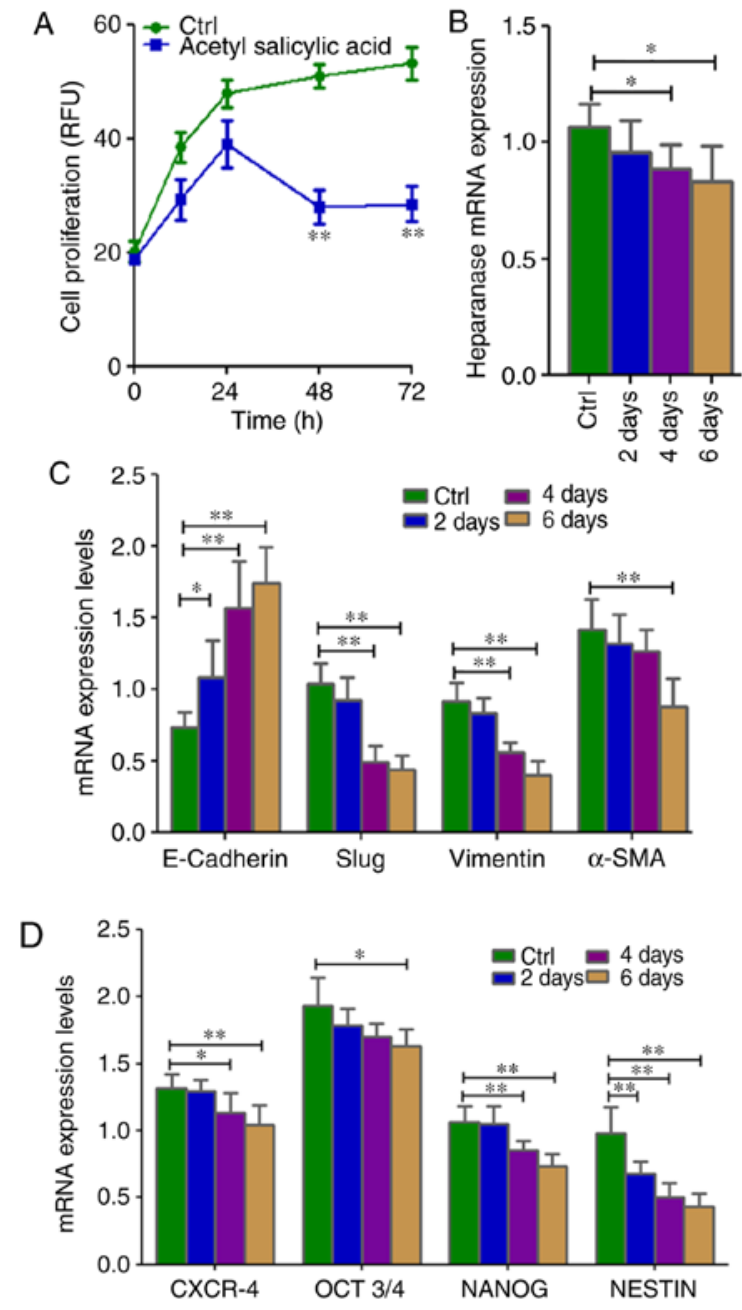

E
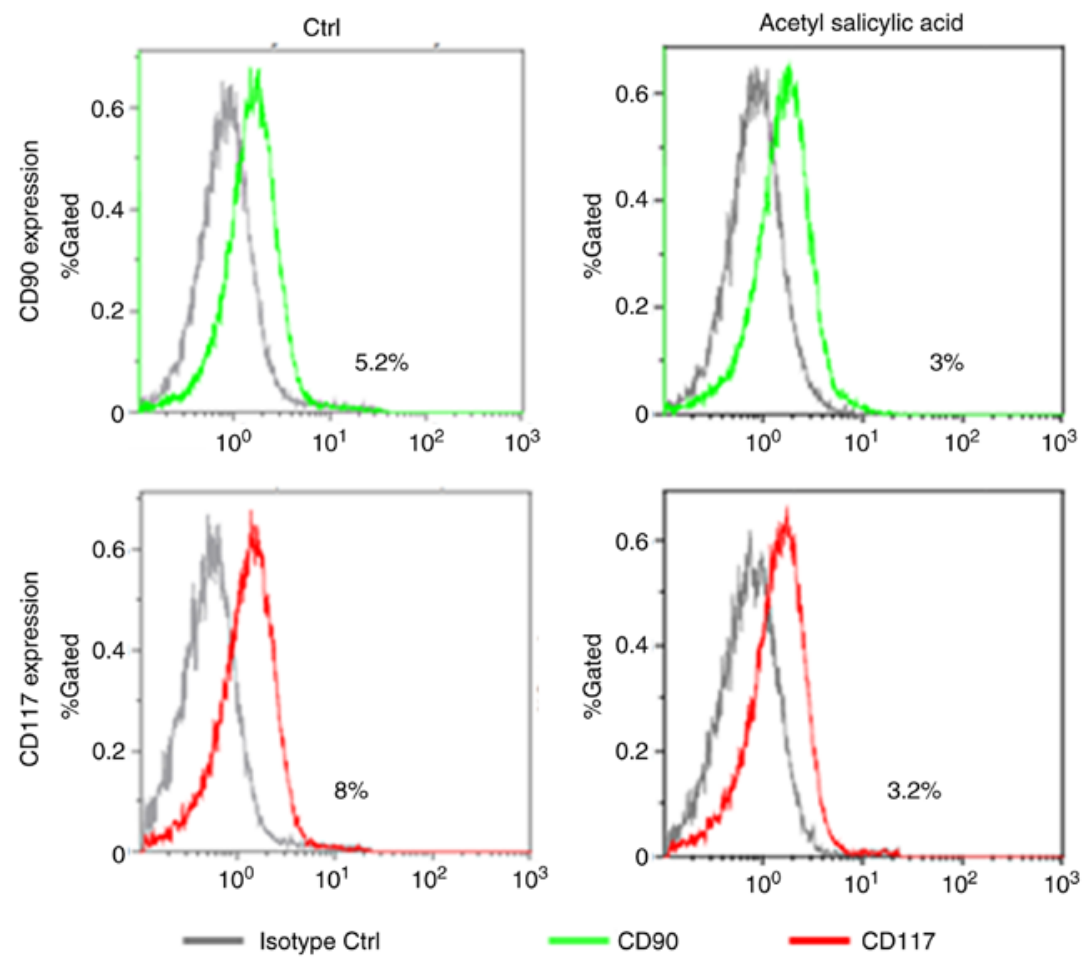

Figure 3. Cell proliferation as well as mRNA expression of EMT-associated genes and stem cell markers in KATO-III following treatment with $4.5 \mathrm{mM}$ acetyl salicylic acid for 6 days. (A) Cell proliferation is inhibited, and (B) the expression of heparanase, (C) mesenchymal markers (Slug, vimentin and $\alpha$-SMA) and (D) stem cell markers CXCR-4, OCT3/4, NANOG and NESTIN as well as (E) CD90 and CD117 were lower, while those of (C) the epithelial marker E-cadherin was higher in KATO-III cells following treatment with acetyl salicylic acid as determined by reverse transcription-quantitative polymerase chain reaction and flow cytometry. ( $\mathrm{P}<0.05$ and ${ }^{* *} \mathrm{P}<0.01$ ). EMT, epithelial-mesenchymal transition; $\alpha$-SMA, $\alpha$-smooth muscle actin; CXCR-4, C-X-C chemokine receptor type 4 ; ОСТ $3 / 4$, octamer-binding transcription factor $3 / 4 ; \mathrm{CD}$, cluster of differentiation. 

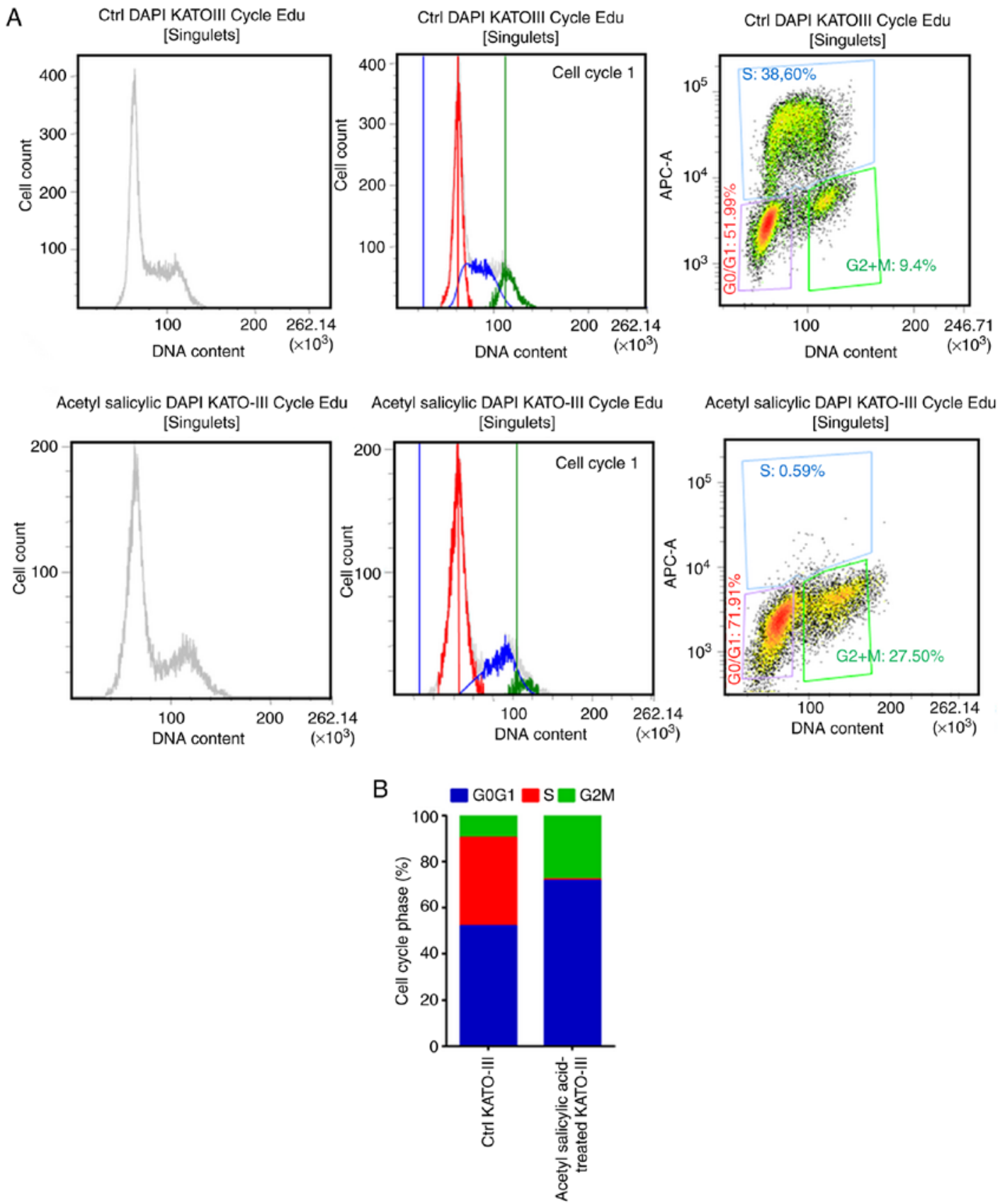

Figure 4. Cell cycle arrest of the KATO-III cell line via flow cytometry following treatment with $4.5 \mathrm{mM}$ acetyl salicylic acid for 4 days. KATO-III cells were analyzed by flow cytometry for cell cycle distribution following treatment with $4.5 \mathrm{mM}$ acetyl salicylic acid for 4 days. (A) G0/G1, S and G2/M phase cells presented as percentages. (B) Data are expressed as the mean \pm standard error of the mean of at least 3 independent experiments.

and osteocytes ( $\mathrm{P}=0.004$; Fig. 5A). This phenomenon was associated with a high expression of $\mathrm{E}$-cadherin $(\mathrm{P}=0.004)$ and the downregulation $(\mathrm{P}=0.005)$ of mesenchymal markers such as Slug, vimentin and $\alpha$-SMA mRNAs (Fig. 5B). By contrast, the conditioned media, except osteocyte-inducer medium, induced the inhibition of KATO-III cell proliferation $(\mathrm{P}=0.002$; Fig. 5D). This inhibition was associated with the downregulation $(\mathrm{P}=0.004)$ of the stem cell markers $\mathrm{CD} 90$ and CD117 (Fig. 5C).

Cell-inducer differentiation medium induces cancer cell differentiation. Adipogenic, chondrogenic, osteogenic and neurogenic differentiation of the KATO-III cell line was confirmed (Fig. 6) by the visualization of intracytoplasmic lipid drops stained red using Oil Red O (Fig. 6A); a blue coloration was observed due to proteoglycan synthesis using Alcian blue (Fig. 6B), a red coloration was observed due to extracellular calcium deposits using Alizarin Red S (Fig. 6C) and dark black-violet was observed due to the extensive somata-associated accumulation of Nissl bodies, respectively (Fig. 6D). These results confirmed the influence of selective medium on the mesenchymal characteristics of the KATO-III cell line.

\section{Discussion}

Apart from elimination therapies that increase the efficacy of cancer treatments, another method to control tumor progression is to induce the differentiation of CSCs (18). In the present 


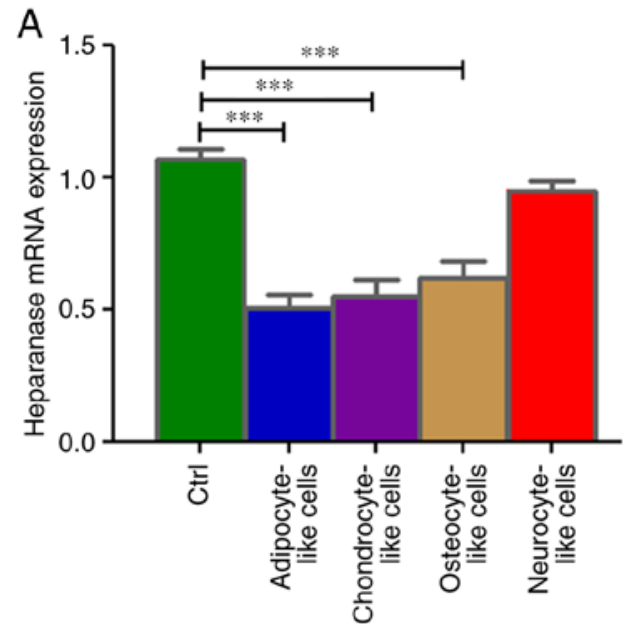

C

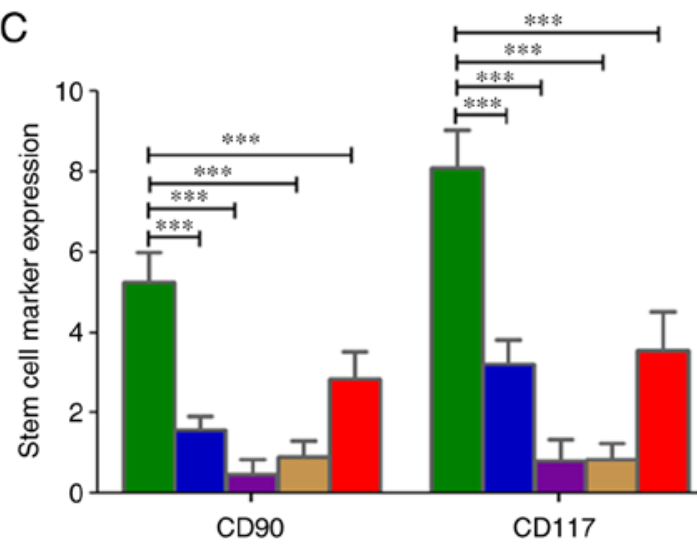

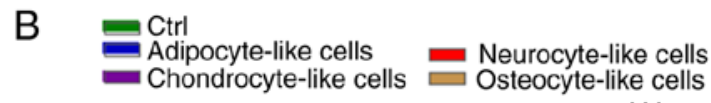

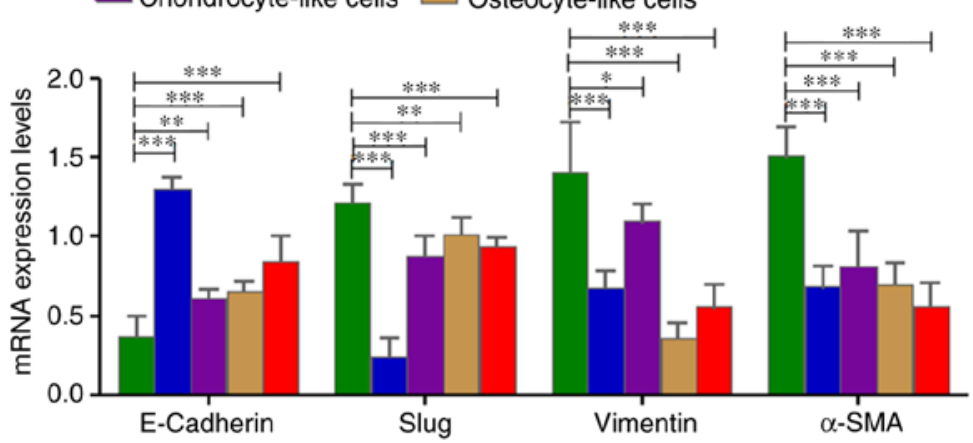

D

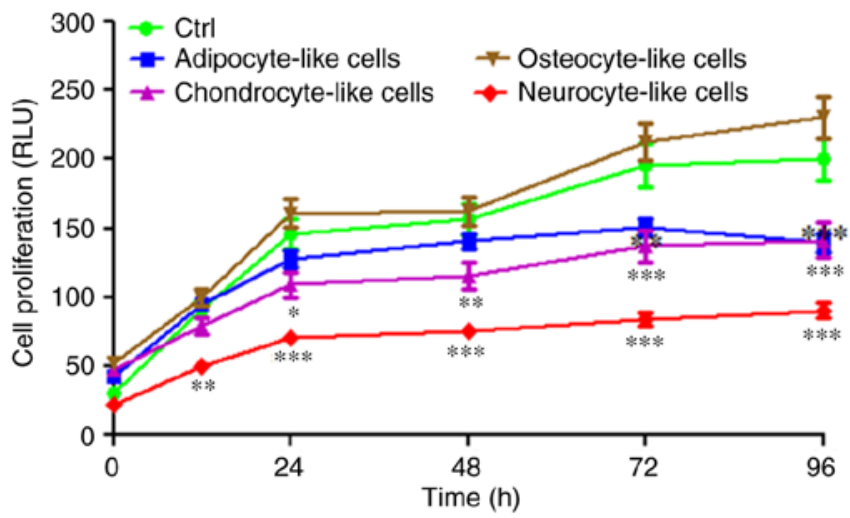

Figure 5. mRNA expression of heparanase and EMT markers via reverse transcription-quantitative polymerase chain reaction and stem cell marker expression via flow cytometry as well as cell proliferation in differentiated KATO-III cells following induction of (A) heparanase, (C) stem cell markers (CD90 and CD117) and (B) mesenchymal markers (Slug, Vimentin and $\alpha$-SMA) were reduced while the epithelial marker (E-cadherin) was increased following the induction of differentiation. (D) Cell proliferation was also significantly inhibited. One- and two-way analysis of variance (ANOVA), followed by post-hoc Bonferroni's multiple comparison test for gene expression and cell proliferation respectively $\left({ }^{*} \mathrm{P}<0.05\right.$, ${ }^{* *} \mathrm{P}<0.01$ and $\left.{ }^{* * * *} \mathrm{P}<0.001\right)$. EMT, epithelial-mesenchymal transition; CD, cluster of differentiation; $\alpha$-SMA, $\alpha$-smooth muscle actin. ANOVA, analysis of variance.

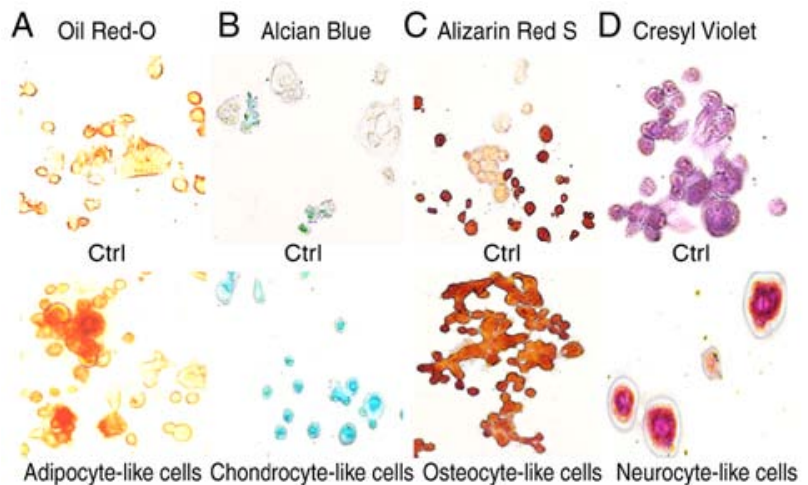

Figure 6. Coloration of differentiated KATO-III cells following induction. (A) Adipogenic, (B) chondrogenic, (C) osteogenic and (D) neurogenic differentiation of KATO-III cells as confirmed by coloration.

study, the differentiation of gastric SRCA cells (KATO-III) were targeted by downregulating EMT and CSC markers. The results revealed that KATO-III cells exhibited 3 phenotypes (adherent, non-adherent and spheroid cluster forms) that are capable of conversion between 2 distinct forms (adherent and non-adherent), a transition we refer to as reversible adaptive plasticity. In addition, no alteration in the RNA expression of EMT-associated molecules was demonstrated via qPCR when grown separately for 1 week. These results are consistent with those of She et al (19) who reported no difference in tumorigenicity in vivo when the side and non-side population of the KATO-III cell line were injected subcutaneously in nude mice.

The present study identified major cytokines significantly secreted by non-adherent cells, including Siglec-5, TGF- $\alpha$, Prolactin, MMP-1, EGF, MMP-13 and SCFR while those of the adherent cells were TIMP-4, Activin A, NGFR, IL-2R $\gamma$ and IL-21R. There is evidence that Siglec-5 is involved in cell-cell interactions and tumor dissemination (20,21), MMP-1 and MMP-13 are implicated in the regulation of extracellular matrix degradation, prolactin was revealed to induce estrogen responsiveness in breast cancer cells (22), TGF- $\alpha$ is implicated in the regulation of cell proliferation and migration through the activation of multiple pathways (23) and EGF and SCFR are thought to be involved in cell differentiation $(24,25)$ indicating that tumor dissemination and cell proliferation may be due to the non-adherent cells of KATO-III. Recent studies have also demonstrated that TIMP-4, as an anti-metalloproteinase, was implicated in cell adhesion (26), Activin A was involved in the regulation of progesterone1 and estradiol production in 
JEG-3 (27) cells as well as the differentiation of granulosa cells via the activation of steroid hormone receptor (28), while NGFR was a differentiating factor for nerve cells (29) and IL-2 served an adjunctive role in IL-21-induced B-cell differentiation (30), suggesting that cell adhesion and differentiation are characteristics of KATO-III adherent cells. The present study also reported estrogen and progesterone receptors in KATO-III cells (data not shown).

The present study also identified the CSC phenotypes of Slug, Snail, vimentin, NANOG, NESTIN, OCT3/4 and CXCR-4. Recent studies have suggested that these CSCs are long-lived, and display quiescent potentials in a dormant state, and are responsible for angiogenic induction, cell proliferation, apoptotic resistance, self-renewal and differentiation $(31,32)$. In the present study, to the best of our knowledge, it was revealed for the first time in a human SRCA cell line (KATO-III) that gastric cancer stem cells exist in the CD90- and CD117-positive fraction that had potential to differentiate into adipocyte, chondrocyte-, osteocyte- and neurocyte-like cells.

The present results revealed that KATO-III differentiated into adipocyte-, chondrocyte, osteocyte and neurocyte-like cells using inducer media. The inhibitory effect of inducer media on KATO-III proliferation, EMT and stem cell marker expression was observed. This inducing media also significantly downregulated the expression of heparanase. This research is consistent with that of Masola et al (33) on the heparanase-mediated EMT of renal tubular cells. Epidemiological evidence has indicated the chemopreventive effect of acetyl salicylic acid in cancer treatment however the molecular basis for this effect is not fully known $(34,35)$. Consistently, it has been reported that regular acetyl salicylic acid users have a lower risk of breast $(36,37)$, gallbladder (38), prostate (39), gastric $(40,41)$ and non-small cell lung cancer (42). A growing body of evidence has revealed that acetyl salicylic acid is the inhibitor of the enzyme, heparanase (43). The aim of the present study was also to focus on the regulation of EMT by altering the expression of EMT markers by using acetyl salicylic acid. This was investigated in the KATO-III cell line, which revealed the significant inhibitory effect of acetyl salicylic acid on EMT and heparanase expression as well as cell proliferation. The present results are in agreement with those of Masola et al (44) who reported heparanase involvement in EMT and the cell proliferation of renal tubular cells. The results of the present study demonstrated that acetyl salicylic acid induced a marked degree of inhibition of EMT and proliferation in the KATO-III cell line. Similarly, acetyl salicylic acid also induced G0/G1 cell cycle arrest up to $20 \%$ and inhibited the $\mathrm{S}$ phase by up to $38 \%$ of the cell population. The limitation of this study was the inability to isolate single and cluster forms of non-adherent KATO-III cells independently due to unavailability of a technique. Incorporating new technologies in future may potentially isolate such types of non-adherent cells for further studies at the protein level.

In conclusion, the inducer media had the ability to induce the differentiation of KATO-III cells. Acetyl salicylic acid has been revealed to be effective in the prevention and treatment of EMT-associated metastasis. Therefore, it is important to continue efforts to identify therapies that can treat cancers no longer susceptible to current treatments. The results of the present study provide a basis for the development of more effective treatment strategies for controlling gastric cancer in the future.

\section{Acknowledgements}

Not applicable.

\section{Funding}

No funding was received.

\section{Availability of data and materials}

The datasets used during the present study are available from the corresponding author upon reasonable request.

\section{Authors' contributions}

SS performed the PCR experiments, the KATO III cell treatment and the flow cytometry. MP interpreted the data for the study. MM substantially contributed to the conception of the study and wrote the study. All authors read and approved the manuscript and agree to be accountable for all aspects of the research in ensuring that the accuracy or integrity of any part of the work are appropriately investigated and resolved.

\section{Ethics approval and consent to participate}

Not applicable.

\section{Patient consent for publication}

Not applicable.

\section{Competing interests}

The authors declare that they have no competing interests.

\section{References}

1. Hu B,ElHajj N, Sittler S,Lammert N, Barnes R and Meloni-Ehrig A: Gastric cancer: Classification, histology and application of molecular pathology. J Gastrointest Oncol 3: 251-261, 2012.

2. Endo K, Maehara Y, Ichiyoshi Y, Kusumoto T, Sakaguchi Y, Ohno S and Sugimachi K: Multidrug resistance-associated protein expression in clinical gastric carcinoma. Cancer 77 (Suppl 8): 1681-1687, 1996

3. Maehara Y, Sakaguchi Y, Moriguchi S, Orita H, Korenaga D, Kohnoe S and Sugimachi K: Signet ring cell carcinoma of the stomach. Cancer 69: 1645-1650, 1992.

4. Shah S, Fourgeaud C, Derieux S, Mirshahi S, Contant G, Pimpie C, Lo Dico R, Soria J, Pocard M and Mirshahi M: The close relationship between heparanase and epithelial mesenchymal transition in gastric signet-ring cell adenocarcinoma. Oncotarget 9: 33778-33787, 2018.

5. Liu YX, Feng JY, Sun MM, Liu BW, Yang G, Bu YN, Zhao M, Wang TJ, Zhang WY, Yuan HF and Zhang XD: Aspirin inhibits the proliferation of hepatoma cells through controlling GLUT1-mediated glucose metabolism. Acta Pharmacol Sin 40: 122-132, 2018.

6. Ducros E, Mirshahi S, Azzazene D, Camilleri-Broët S, Mery E, Al Farsi H, Althawadi H, Besbess S, Chidiac J, Pujade-Lauraine E, et al: Endothelial protein C receptor expressed by ovarian cancer cells as a possible biomarker of cancer onset. Int J Oncol 41: 433-440, 2012. 
7. Kaci R, Shahid S, Réa L, Philipe B, Amu T, Marc P and Massoud M: Neural signature expressed by cells from ovarian carcinoma (A Case Report). Immunochem Immunopathol 1: 2, 2015.

8. Flynn PJ, Miller WJ, Weisdorf DJ, Arthur DC, Brunning R and Branda RF: Retinoic acid treatment of acute promyelocytic leukemia: In vitro and in vivo observations. Blood 62: 1211-1217, 1983.

9. de Thé H Pandolfi PP and Chen Z: Acute promyelocytic leukemia: A paradigm for oncoprotein-targeted cure. Cancer Cell 32: 552-560, 2017.

10. Kastner P, Lawrence HJ, Waltzinger C, Ghyselinck NB, Chambon P and Chan S: Positive and negative regulation of granulopoiesis by endogenous RARalpha. Blood 97: 1314-1320, 2001.

11. Werner S, Stenzl A, Pantel K and Todenhöfer T: Expression of epithelial mesenchymal transition and cancer stem cell markers in circulating tumor cells. Adv Exp Med Biol 994: 205-228, 2017.

12. Zabala M, Lobo NA, Qian D, van Weele LJ, Heiser D and Clarke MF: Overview: Cancer stem cell self-renewal. In: Cancer Stem Cells. Academic Press, pp25-58, 2016.

13. Ginestier C, Wicinski J, Cervera N, Monville F, Finetti P, Bertucci F, Wicha MS, Birnbaum D and Charafe-Jauffret E: Retinoid signaling regulates breast cancer stem cell differentiation. Cell Cycle 8: 3297-3302, 2009.

14. Mani SA, Guo W, Liao MJ, Eaton EN, Ayyanan A, Zhou AY, Brooks M, Reinhard F, Zhang CC, Shipitsin M, et al: The epithelial-mesenchymal transition generates cells with properties of stem cells. Cell 133: 704-715, 2008

15. Brambilla E, Moro D, Gazzeri S, Brichon PY, Nagy-Mignotte H, Morel F, Jacrot M and Brambilla C: Cytotoxic chemotherapy induces cell differentiation in small-cell lung carcinoma. J Clin Oncol 9: 50-61, 1991.

16. Azzazene D, Al Thawadi H, Al Farsi H, Besbes S, Geyl C, Mirshahi S, Pardo J, Faussat AM, Jeannette S, Therwath A, et al: Plasma endothelial protein $\mathrm{C}$ receptor influences innate immune response in ovarian cancer by decreasing the population of natural killer and TH17 helper cells. Int J Oncol 43: 1011-1018, 2013.

17. Livak KJ and Schmittgen TD: Analysis of relative gene expression data using real-time quantitative PCR and the 2(-Delta Delta C(T)) method. Methods 25: 402-408, 2001.

18. Batlle E and Clevers H: Cancer stem cells revisited. Nat Med 23 : 1124-1134, 2017

19. She JJ, Zhang PG, Wang X, Che XM and Wang ZM: Side population cells isolated from KATO III human gastric cancer cell line have cancer stem cell-like characteristics. World J Gastroenterol 18: 4610-4617, 2012.

20. Crocker PR: Siglecs: Sialic-acid-binding immunoglobulin-like lectins in cell-cell interactions and signalling. Curr Opin Struct Biol 12: 609-615, 2002.

21. Liu FT and Rabinovich GA: Galectins as modulators of tumour progression. Nat Rev Cancer 5: 29-41, 2005.

22. Gutzman JH, Miller KK and Schuler LA: Endogenous human prolactin and not exogenous human prolactin induces estrogen receptor $\alpha$ and prolactin receptor expression and increases estrogen responsiveness in breast cancer cells. J Steroid Biochem Mol Biol 88: 69-77, 2004.

23. Wang C, Lv X, Jiang C, Cordes CM, Fu L, Lele SM and Davis JS: Transforming growth factor alpha $(\mathrm{TGF} \alpha)$ regulates granulosa cell tumor (GCT) cell proliferation and migration through activation of multiple pathways. PLoS One 7: e48299, 2012.

24. Barberán $\mathrm{S}$ and Cebrià $\mathrm{F}$ : The role of the EGFR signaling pathway in stem cell differentiation during planarian regeneration and homeostasis. Semin Cell Dev Biol 87: 45-57, 2019.

25. Wang H, Pierce LJ and Spangrude GJ: Distinct roles of IL-7 and stem cell factor in the OP9-DL1 T-cell differentiation culture system. Exp Hematol 34: 1730-1740, 2006.
26. Radisky ES and Radisky DC: Matrix metalloproteinase-induced epithelial-mesenchymal transition in breast cancer. J Mammary Gland Biol Neoplasia 15: 201-212, 2010.

27. Ni X, Luo S, Minegishi T and Peng C: Activin A in JEG-3 cells: Potential role as an autocrine regulator of steroidogenesis in humans. Biol Reprod 62: 1224-1230, 2000.

28. Ueno N, Nishimatsu S and Murakami K: Activin as a cell differentiation factor. Prog Growth Factor Res 2: 113-124, 1990.

29. Lu Y, Wang J, Xu Y, Koch AE, Cai Z, Chen X, Galson DL, Taichman RS and Zhang J: CXCL16 functions as a novel chemotactic factor for prostate cancer cells in vitro. Mol Cancer Res 6 : 546-554, 2008.

30. Berglund LJ, Avery DT, Ma CS, Moens L, Deenick EK, Bustamante J, Boisson-Dupuis S, Wong M, Adelstein S, Arkwright PD, et al: IL-21 signalling via STAT3 primes human naive $B$ cells to respond to IL-2 to enhance their differentiation into plasmablasts. Blood 122: 3940-3950, 2013.

31. Bao B, Ahmad A, Azmi AS, Ali S and Sarkar FH: Overview of cancer stem cells (CSCs) and mechanisms of their regulation: Implications for cancer therapy. Curr Protoc Pharmacol 14: 14-25, 2013

32. Soltysova A, Altanerova V and Altaner C: Cancer stem cells. Neoplasma 52: 435-440, 2005

33. Masola V,Zaza G, Granata S, Gambaro G, Onisto M and Lupo A: Everolimus-induced epithelial to mesenchymal transition in immortalized human renal proximal tubular epithelial cells: Key role of heparanase. J Transl Med 11: 292, 2013.

34. Thun MJ, Jacobs EJ and Patrono C: The role of aspirin in cancer prevention. Nat Rev Clin Oncol 9: 259-267, 2012

35. Mohammed I, Musa MO and Umar A: Effects of acetylsalicylic acid and salicylic acid on the growth of HeLa cervical cancer cells line. Am J Pharm Pharmacol 1: 32-44, 2014.

36. Mangiapane S, Blettner M and Schlattmann P: Aspirin use and breast cancer risk: A meta-analysis and meta-regression of observational studies from 2001 to 2005. Pharmacoepidemiol Drug Saf 17: 115-124, 2008

37. Takkouche B, Regueira-Méndez $\mathrm{C}$ and Etminan M: Breast cancer and use of nonsteroidal anti-inflammatory drugs: A meta-analysis. J Natl Cancer Inst 100: 1439-1447, 2008.

38. Liu E, Sakoda LC, Gao YT, Rashid A, Shen MC, Wang BS, Deng J, Han TQ, Zhang BH, Fraumeni JF Jr and Hsing AW: Aspirin use and risk of biliary tract cancer: A population-based study in Shanghai, China. Cancer Epidemiol Biomarkers Prev 14: 1315-1318, 2005

39. Dasgupta K, Di Cesar D, Ghosn J, Rajan R, Mahmud S and Rahme E: Association between nonsteroidal anti-inflammatory drugs and prostate cancer occurrence. Cancer J 12: 130-135, 2006.

40. Jolly K, Cheng KK and Langman MJ: NSAIDs and gastrointestinal cancer prevention. Drugs 62: 945-956, 2002.

41. Husain SS, Szabo IL and Tarnawski AS: NSAID inhibition of GI cancer growth: Clinical implications and molecular mechanisms of action. Am J Gastroenterol 97: 542-553, 2002.

42. Van Dyke AL, Cote ML, Prysak G, Claeys GB, Wenzlaff AS and Schwartz AG: Regular adult aspirin use decreases the risk of non-small cell lung cancer among women. Cancer Epidemiol Biomarkers Prev 17: 148-157, 2008.

43. Dai X, Yan J, Fu X, Pan Q, Sun D, Xu Y, Wang J, Nie L, Tong L, Shen A, et al: Aspirin inhibits cancer metastasis and angiogenesis via targeting heparanase. Clin Cancer Res 23: 6267-6278, 2017.

44. Masola V, Gambaro G, Tibaldi E, Brunati AM, Gastaldello A, D'Angelo A, Onisto M and Lupo A: Heparanase and syndecan-1 interplay orchestrates fibroblast growth factor-2-induced epithelial-mesenchymal transition in renal tubular cells. J Biol Chem 287: 1478-1488, 2012.

(i) $\Theta$ This work is licensed under a Creative Commons Attribution-NonCommercial-NoDerivatives 4.0 International (CC BY-NC-ND 4.0) License. 